\title{
Determination of suitable parameters for Battery Analysis by Electrochemical Impedance Spectroscopy
}

\author{
Yoana Fernández. Pulido ${ }^{a^{*}}$, Cecilio Blanco ${ }^{\mathrm{a}}$, David Anseán ${ }^{\mathrm{a}}$, Víctor M. García ${ }^{\mathrm{b}}$, Francisco Ferrero ${ }^{\mathrm{a}}$, Marta \\ Valledor ${ }^{\mathrm{a}}$ \\ ${ }^{a}$ Department of Electrical Engineering, University of Oviedo, 33203 Gijón, Spain
${ }^{\mathrm{b}}$ Department of Physical and Analytical Chemistry, University of Oviedo, 33203 Gijón, Spain
}

\begin{abstract}
Electrochemical Impedance Spectroscopy (EIS) is one of the most powerful tools for the study of batteries. The applied AC current, range of frequency sweep, points per decade represented, length of the pause time after a change in the state of charge (SOC) and length of the pause time after a change in the ambient temperature must have suitable values to obtain useful results from EIS tests. A method to determine and optimize these parameters is presented in this paper. It is based on the limits imposed by the battery, the tests carried out, the instruments employed and the use of Kramers-Kronig relations. The method has been checked using two kinds of lithium batteries: a lithium iron phosphate (LFP) battery and a lithium cobalt oxide (LCO) battery.
\end{abstract}

Keywords - Lithium batteries, Electrochemical Impedance Spectroscopy (EIS)

\section{Introduction}

$I_{\mathrm{d}}^{\mathrm{N}}$ $\mathrm{N}$ recent years, Li batteries have been widely used [1] in different applications due to their high energy and power density, low self-discharge, low maintenance, variety of technologies available, long life, environmentally friendliness and low toxicity [2], [3].

Li-ion battery technology is accordingly considered for a wide range of applications such as renewables, automotive industry and mobile electronic devices [4], [5].

Electrochemical Impedance Spectroscopy (EIS) is one of the most useful techniques for characterizing and modeling batteries [6] as it can provide detailed information on the systems under non-destructive examination [7].

EIS allows the development of dynamic battery cell models whose elements can be allied to the physico-chemical processes that arise inside the battery [8],[9],[10]. EIS tests also allow the study of electrochemical mechanisms, reaction kinetics [11],[12],[13],[14], detection of localized corrosion [15], battery life performance [16], state of charge (SOC) [17], cathode [18],[19],[21],[22], [23] and anode [24], [25], [26], [27], [20], [28] materials in lithium batteries, the kinetics of lithium-ion intercalation [7], [29], factors responsible for the loss of capacity [11], lithium diffusion coefficients [8], factors responsible for overall impedance during Li-cycling [27] and parameters related to the transport of intercalation materials [30].

EIS tests can be carried out in potentiostatic or galvanostatic mode. In potentiostatic mode, a small sinusoidal AC voltage is applied over a given range of frequency sweep to a battery and the resulting battery current is measured. In galvanostatic mode, a small sinusoidal AC current is applied over a given range of frequency sweep to a battery and the resulting battery voltage is measured [31], [32]. Potentiostatic mode is poorly suited for batteries due to their low impedance: a small error in the applied AC voltage, e.g. $1 \mathrm{mV}$ [33], could produce an unexpected high current that could modify the battery SOC. However, as a galvanostat can easily control the applied current to an accuracy of a few milliamps, the battery voltage and SOC are usually unaffected when the galvanostat is connected to the battery [34]. Consequently, galvanostatic mode is recommended for batteries [34].

There are on line EIS techniques for batteries for on board use of a Battery Management System (BMS) operating on line in an electrical vehicle (EV). These techniques allow the onboard impedance to be obtained using techniques with suitable excitation, simultaneously including a number of frequencies, such as pseudo random binary sequences (PRBS). These types of techniques are more likely to generate noise and the impedance thus obtained has a greater error in high frequencies than when using classical EIS techniques. Other qualities of these techniques are that they are cheap and fast and that is possible to track the changes in impedance during the use of the EV to obtain on-board state of health (SOH) information [35]. However, the present study focuses on a laboratory EIS because we wish to obtain the impedance function of cells in a wave frequency range in the most robust and accurate way possible.

Nyquist plots, which plot the imaginary part of the impedance versus the real part, are one of the most useful plots to represent and analyze the results of EIS tests [36], [37]. Optimum Nyquist plots should be repeatable, not have noise and show five different sections, each one related to a particular process. From the highest to the lowest frequencies, see Fig. 1, Section 1 shows inductive behavior. Section 2 shows the ohmic resistance of the battery, which is determined by the intersection of the plot with the real axis. Section 3 is associated with the solid electrolyte interphase (SEI) on the graphite electrode. Section 4 represents the double layer capacitance (DL), the charge transfer (CT) resistance at the electrodes, and the surface film (SF) resistance on the cathode. Sometimes the lowest frequency region of Section 4 contains 


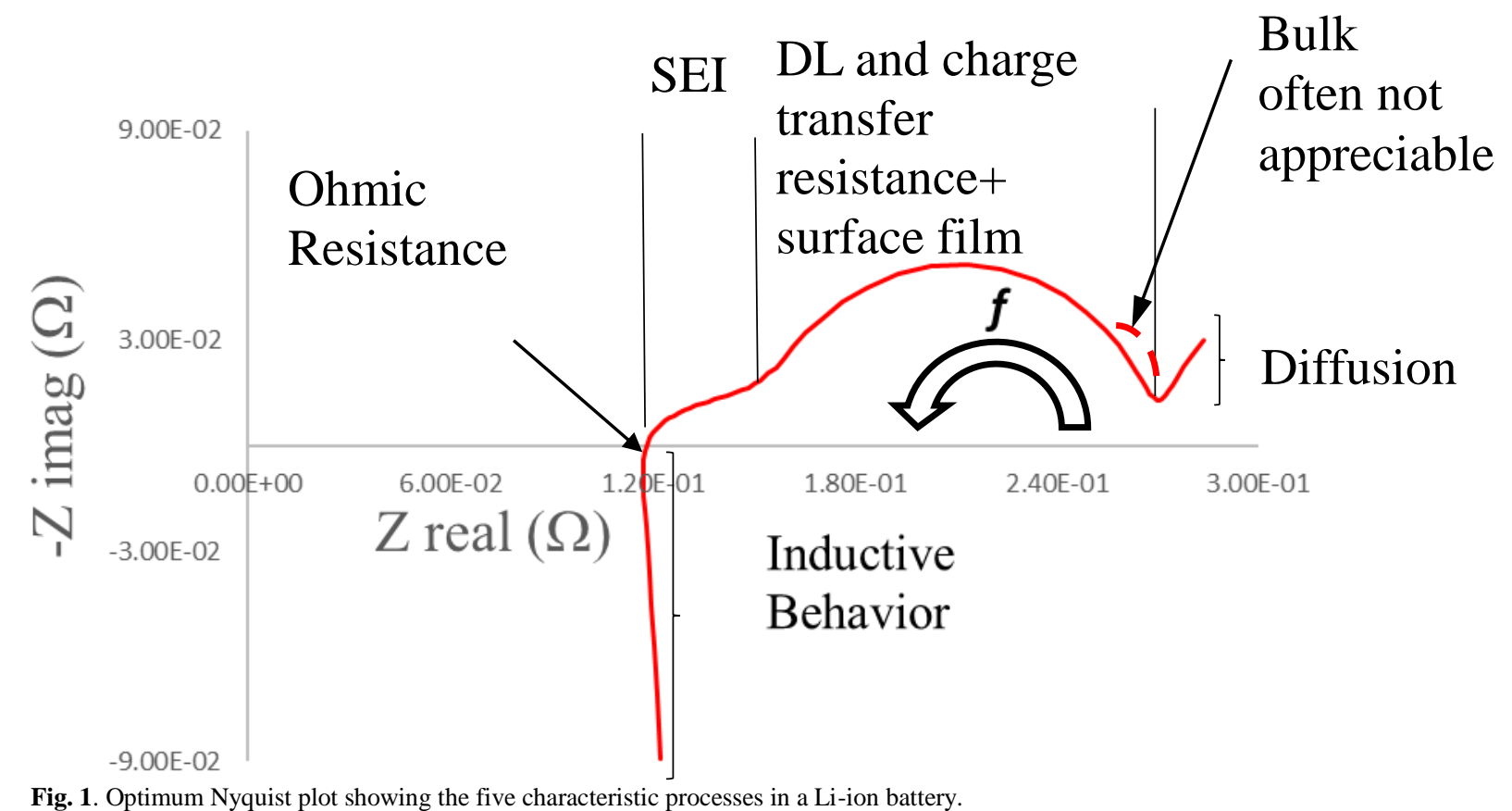

an arc, associated with the bulk impedance of the electrodes. This impedance is due to the resistance to the flow of electricity through the interior of the active particles, the resistance to the flow of ions through the pores of the composites, and non-homogeneous coating of the collectors [38]. Section 5 represents the diffusion process [39], [40], [41], [42], [43]. It should be noted, however, that experimental spectra do not always show all the sections as represented in Fig. 1. The time constants of the processes in Sections 3 and 4 are similar, so these processes are not always observable or separable [38], [44].

The use of the Nyquist plot representing the impedance of a lithium battery, have a lot of research interest and focuses on obtaining information about batteries under study [10], [37], [40], [45]

To obtain a valid and useful Nyquist plot from an EIS test for subsequent analysis is not straightforward. As stated previously, valid Nyquist plots should be repeatable, show characteristic processes taking place in the battery and not have noise. The limits within which the EIS test is performed needs to be determined to ensure compliance with these requirements. These limits are defined by a set of parameters of the EIS test: applied DC-offset, applied AC current, range of frequency sweep, number of points measured by decade, length of the pause time after a change in temperature and length of the pause time after a change in battery SOC.

Obtaining these parameters is not straightforward and, to the best of our knowledge, the scientific literature contains only some general recommendations [46] regarding how to determine the value of these parameters.

Many studies present EIS experiments but do not explain how they obtain suitable values for these parameters in order to obtain a valid Nyquist plot [10], [37], [40], [45], [46]. One study explains that it is necessary to perform preliminary tests to determine the suitable parameters to carry out the EIS experiment properly, although the method to obtain these parameters is not explained [47] .

To fill this gap, a systematic method to carry out preliminary tests to obtain suitable values for these parameters (applied DC-offset, applied AC current, range of frequency sweep, number of points measured by decade, length of the pause time after a change in temperature and length of the pause time after a change) is presented in this paper.

Impedances obtained from the EIS test depends on temperature, the state of charge (SOC) of the battery or the number of charge/discharge cycles the battery has undergone [38]. The value of these parameters could thus be affected by these factors though the proposed method to determine the parameters is not affected.

A 2.6 Ah Li-on battery (with lithium iron phosphate and graphite as active materials) and a $1.35 \mathrm{Ah} \mathrm{Li-ion} \mathrm{battery}$ (with lithium cobalt oxide and graphite as active materials) were used in this research study. In this method, the limits imposed by the battery, the instruments employed and the type of test are taken into account and Kramers-Kronig (K-K) relations are used to select the best possible values [48].

The paper is organized as follows: Section 2 provides a brief description of K-K relations, Section 3 reports the materials and equipment used in the experiments, Section 4 describes the determination procedure, Section 5 shows the experimental results obtained with a lithium iron phosphate (LFP) battery and a lithium cobalt oxide (LCO) battery, while Section 6 presents the conclusions.

\section{Theoretical Aspects}

The measurement and interpretation of an EIS spectrum, as shown in Fig. 1, is only valid for linear and stationary systems. Both conditions are often ensured by repetitions of the tests. If the spectra obtained from repeated tests with 
slightly different currents or voltages are identical (except for random errors), the system is considered linear. If the spectra obtained from repeated tests with the same parameters are identical (except for random errors), the system is considered stationary.

$\mathrm{K}-\mathrm{K}$ relations constitute another way to confirm these two conditions, which are necessary to validate an EIS test. K-K relations are bidirectional mathematical relations linking the real and imaginary parts of any complex function that is analytic in the upper half-plane. These relations are often used to calculate the real from the imaginary part of response functions in physical systems, because, for stable systems, causality implies the condition of analyticity, while conversely, analyticity implies causality in the corresponding stable physical system [49].

The use of $\mathrm{K}-\mathrm{K}$ relations to verify impedance data. was derived from the work of Kramers and Kronig [50], [51], [52] by Bode, who particularized the method to the connection between the amplitude and the phase for electrical impedances[53]. Mc Donald, Orazem and other authors subsequently applied it to EIS [48], [54], [53] . That is, K-K relations can be used to determine whether the impedance spectrum of a given system has been influenced by bias errors

$$
W_{i}=\left[\left(Z_{r e, i}\right)^{2}+\left(Z_{i m, i}\right)^{2}\right]^{-1}
$$

the values of goodness of fit in this study correspond to the minimum value obtained for this sum of squares. The mean systematic error is the square root of the sum of squares.

To avoid the use of CNLS-fitting and hence the set of starting values, in 1995 Boukamp [57] proposed a means for performing the fit via linear equations, eliminating possible non convergence issues. This method also uses the equivalent circuit proposed by Agarwal [56]. This is the approach used in the method proposed here [34].

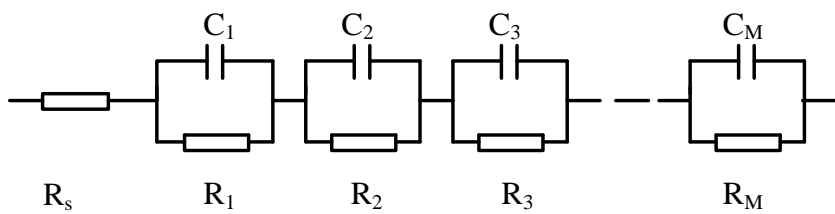

Figure 2. Equivalent circuit model for lineal Kramers-Kronig transform test of date in the impedance representation.

In this method, the $M$ measured experimental data $\left(Z_{\mathrm{re}}\right.$, $\left.Z_{\mathrm{im}}\right)_{\mathrm{i}=1, \mathrm{M}}$ are fitted to the theoretical impedance of the equivalent circuit in Fig. 2 with the same number, M, of Voigt elements:

$$
\begin{aligned}
& Z_{r e}\left(\omega_{i}\right)=R_{s}+\sum_{k=1}^{M} \frac{R_{k}}{1+\left(\omega_{i} \tau_{k}\right)^{2}} \\
& Z_{i m}\left(\omega_{i}\right)=-\sum_{k=1}^{M} \frac{\omega_{i} R_{k} \tau_{k}}{1+\left(\omega_{i} \tau_{k}\right)^{2}}
\end{aligned}
$$

caused by non-linearity or time-dependent phenomena [55]. However, K-K relations require integration over the frequency range from zero to infinity, so extrapolation to zero and infinite frequency must be performed.

To avoid extrapolation, the use of a generalized model consisting of a resistor in series, Rs, with M Voigt elements, i.e., $-\mathrm{Rs}-(\mathrm{RC})_{\mathrm{m}=1, \mathrm{M}}$ is proposed by Agarwal [56]. A Voigt element is a resistor and a capacitor connected in parallel, where the parameter $M$ is generally equal to the number of complex plane data points in the spectrum. This model is by definition K-K compliant. Thus, if a good fit of this model to the measured data can be obtained, the data must also be K-K compliant. However, this method requires complex nonlinear least-squares (CNLS) fitting and a set of starting values. The CNLS method minimizes the sum of the following squared measurement/model deviations:

$$
S^{2}=\sum_{i=1}^{M} W_{i}\left(\left[Z_{r e, i}-Z_{r e}\left(\omega_{i}\right)\right]^{2}+\left[Z_{i m, i}-Z_{i m}\left(\omega_{i}\right)^{2}\right]\right)
$$

Using a weighting per module of the experimental impedances

where the time constants $\tau_{k}=R_{k} C_{k}=\left[\omega_{\mathrm{k}}\right]^{-1}$ and the frequencies are logarithmically located along the frequency axis.

Hence, a) a valid impedance fit of the Rs-(RC) $)_{m=1, M}$ model to the measured experimental data is made without the need to make extrapolations to zero or infinite frequency regions, as a comprehensive version of the original $\mathrm{K}-\mathrm{K}$ transformations would require; and $b$ ) the fitting method becomes linear and the problem of suitable initial values required in the original Agarwal method is avoided [58].

The systematic error detected by $\mathrm{K}-\mathrm{K}$ relations includes the nonlinearity error of the system arising from possible high currents and the non-stationarity error associated with the temporal evolution of the system (an electrochemical cell) during measurement. The systematic error due to an inappropriate impedance model is automatically excluded according to Agarwal [40]. Systematic errors derived from a very high frequency inductive tail may pass the K-K test and remain masked in a low goodness-of-fit value. However, this kind of error is usually associated with instrumentation wiring, so it is easily identifiable and can be subsequently ruled out.

Boukamp's method, however, requires near-perfect data; i.e., not only systematic errors must be low but so must random errors. As random errors may pass the K-K test and remain masked, the distribution graphs of the following residuals versus the $\log$ frequency were calculated and analyzed:

$$
\begin{aligned}
& \Delta_{r e}\left(\omega_{i}\right)=\frac{Z_{r e, i}-Z_{r e}\left(\omega_{i}\right)}{\left|Z\left(\omega_{i}\right)\right|}, \\
& \Delta_{i m}\left(\omega_{i}\right)=\frac{Z_{i m, i}-Z_{i m}\left(\omega_{i}\right)}{\left|Z\left(\omega_{i}\right)\right|}
\end{aligned}
$$


where $Z_{\mathrm{re}, \mathrm{i}}$ and $Z_{\mathrm{im}, \mathrm{i}}$ are the real and imaginary parts of the ith data set (at frequency $\left.\omega_{\mathrm{i}}\right)$ and $Z_{\mathrm{re}}\left(\omega_{\mathrm{i}}\right)$ and $Z_{\mathrm{im}}\left(\omega_{\mathrm{i}}\right)$ are the real and imaginary parts of the modeling function for $\omega_{\mathrm{i}} .\left|\mathrm{Z}\left(\omega_{\mathrm{i}}\right)\right|$ is the vector length (absolute value) of the modeling function, see Equations (3) and (4). These residuals include not only the systematic error but also the random error. The structure of the random error (noise) has also been checked by means of these residuals.

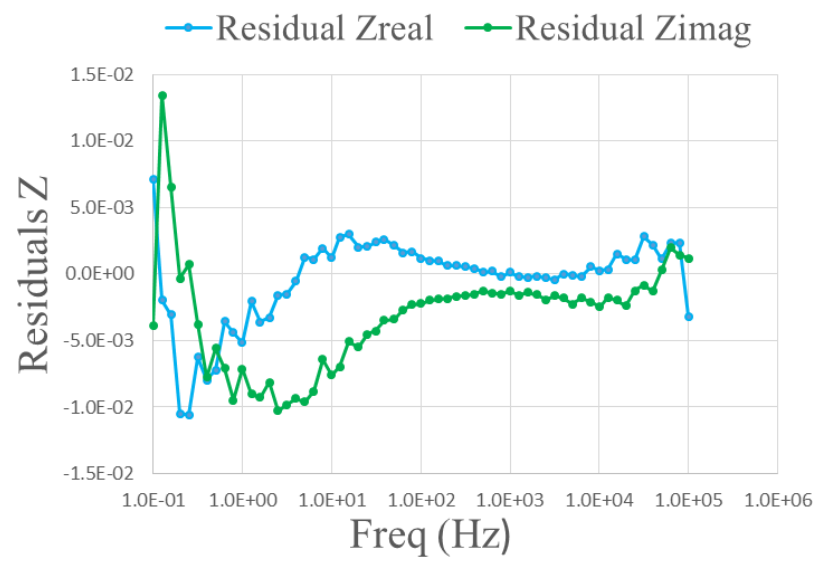

Figure 3: Large and systematic residual errors

Figs. 3 and 4 show the graphs of residuals of different EIS spectra for the same battery. The graphs shown in Fig. 3 correspond to an EIS test with large systematic errors that has not passed the K-K test. K-K relations detect this systematic error and no additional study of residuals will be necessary, while residuals confirm the large systematic error.

Fig. 4 shows the graphs of residuals of a useful set of measured data: systematic and random errors are small. These data have passed the K-K test and, as expected, the graphs of residuals confirm that systematic error is small. To be useful, however, the data must present a small random error, as shown in Fig. 4.

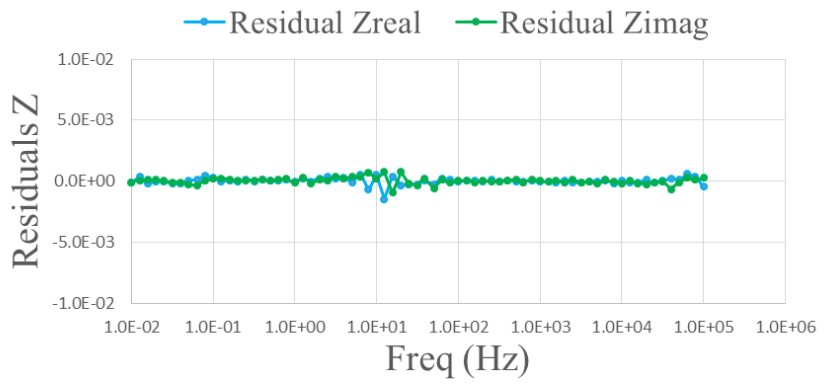

Figure 4: Small systematic and random residual errors corresponding to a useful EIS test.

Besides the application of the K-K test to check the quality of the spectra, it should be borne in mind that spectra must be repeatable. An example of the repeatability of this method is shown in Fig. 5 in which the spectra were recorded five days apart, but are identical.

\section{Materials and equipment}

The experiments were performed on two lithium batteries, a LFP battery and a LCO battery. A summary of the characteristics of the tested batteries is given in Table I. The batteries were placed in an environmental chamber to maintain constant ambient temperature throughout the tests.

A Gamry Reference 3000 Potentiostat/Galvanostat was used in this study. This device allows currents of up to $3 \mathrm{~A}$, a minimum frequency of $10 \mu \mathrm{Hz}$ and a maximum frequency of $1 \mathrm{MHz}$. The maximum number of measured points per decade is 32,000 . This is not a serious limitation, as most impedance spectra contain less than 100 points.

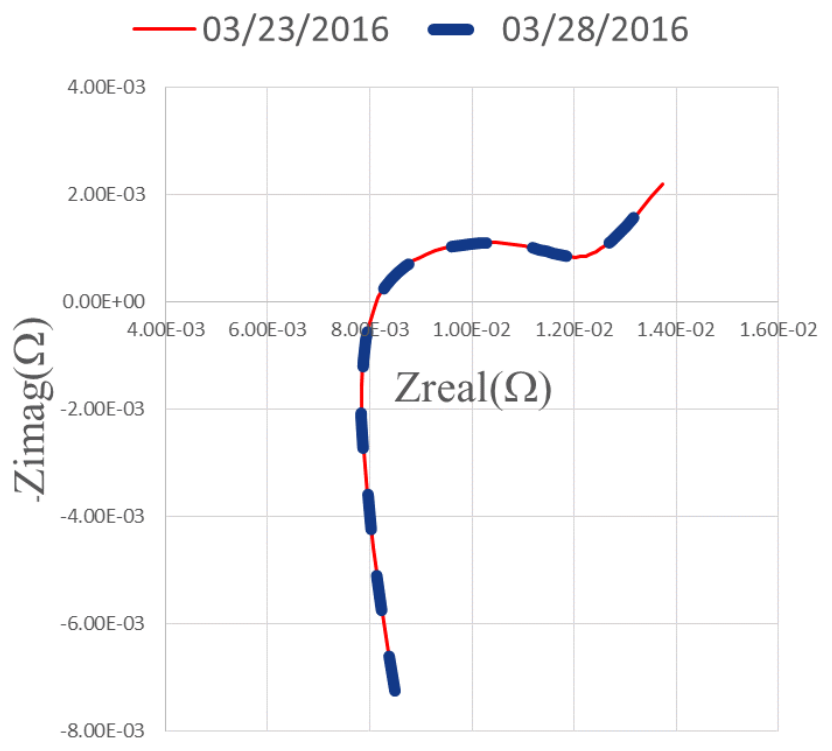

Figure 5: Nyquist plots performed with five days apart.

The Gamry Reference 3000 calculates K-K relations and shows them in a tab that displays a grid containing the "Goodness of Fit" and a plot of the relative residual errors in the real and imaginary parts of the experimental data. A small "goodness-of-fit" value indicates that the results contain linear, causal and stable data [57]. The plots of relative residual errors enable checking whether the random errors are low.

\section{Determination Procedure}

The procedure started with the commissioning of the batteries, in which they were identified and weighed.

Then, in the case of fresh batteries, they were conditioned according to USABC recommendations [59], [60]. If the batteries were not fresh, the conditioning consisted of four charge and discharge cycles at $\mathrm{C} / 2$ [61]. After commissioning and conditioning, preliminary tests were carried out to determine the suitable parameters for EIS tests. Following this step, the EIS tests were conducted. The flow diagram of the experimental procedures is shown in Fig. 6. 


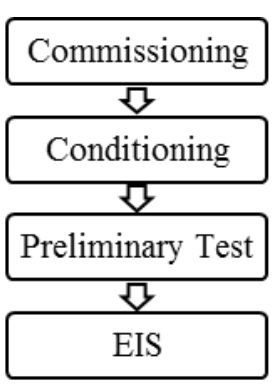

Figure 6. Flow diagram of the experimental procedures

The purpose of the preliminary tests was to determine the suitable values of the following parameters: DC offset, AC current amplitude, range of frequency sweep, number of measured points per decade, length of the pause time after change in temperature and length of the pause time after a change in SOC. Once a parameter had been optimized, this value was used in the EIS experiments to determine the next parameter.

\subsection{DC offset}

EIS tests can be classified into three different types: a) tests with zero DC current and low AC current amplitude; b) tests with zero DC current and high $\mathrm{AC}$ current amplitude and c) tests with non-zero DC current and low AC current amplitude.

In our case the first type of test was performed to study the batteries of interest. In the test DC current is not applied to the battery because a change in the SOC during the test is not desired. Thus, the selected DC current, and hence, the selected DC offset, is zero.

\subsection{AC current amplitude}

This parameter determines the amplitude of the AC signal applied to the cell. Its value must fall within a suitable range that depends on the galvanostat, the battery and the maximum frequency the range of the frequency sweep.

The upper limit depends on the galvanostat and the battery. The lower limit depends on the galvanostat, the maximum frequency of the range of the frequency sweep and the absence of noise in the spectrum.

Each galvanostat has its own upper limit for current. When the DC offset is zero, the maximum peak current allowed by the Gamry Reference 3000 is $3 \mathrm{~A}$, although the AC current should be entered in the instrument in rms amps [33].

The internal impedance of the battery limits the maximum current. To keep the battery in a linear region of its current to voltage curve, the voltage amplitude should not exceed 35 $\mathrm{mV}$, with $7 \mathrm{mV}$ being suitable for low impedance batteries [62]. Thus, the upper limit for the current imposed by the battery is a function of its internal impedance.

As the galvanostat and the battery set their own upper limits, the lower of these two upper limits is selected.

As regards the lower limit, the limit imposed by the Gamry Reference 3000 galvanostat is $1 \mathrm{nA}$.

The maximum frequency obtained in the test also imposes a lower current limit in order to keep the battery in a linear region of its current to voltage curve. When the DC current is zero, the minimum current should be greater than $5 \mu \mathrm{A}$ times the ratio of the maximum frequency of the test divided by 100 $\mathrm{kHz}$ [63]. Thus, the lower limit imposed by the galvanostat is discarded.

However, to obtain a noise-free battery voltage, the current must have a minimum value, which is usually higher than the lower limits imposed by the galvanostat and the maximum frequency obtained in the test. Thus, the lower limit will be imposed by the absence of noise and it will not be necessary to know the maximum frequency to determine the lower limit of the current.

In the proposed method, the AC current value will be the one that falls within the lower and upper limits, whose EIS spectrum shows (if possible) all the characteristic behavior of a battery, see Fig. 1, and has the smallest Goodness of Fit of $\mathrm{K}-\mathrm{K}$.

TABLE I

MAIN CHARACTERISTICS OF THE TESTED BATTERIES

\begin{tabular}{ccc}
\hline \hline & Cell 1 & Cell 2 \\
\hline Technology & LCO & LFP \\
Nominal Capacity & $1.35 \mathrm{Ah}$ & $2.6 \mathrm{Ah}$ \\
Maximum Continuous & $1.35 \mathrm{~A}(1 \mathrm{C})$ & $70 \mathrm{~A}(27 \mathrm{C})$ \\
$\begin{array}{c}\text { Discharge } \\
\text { Maximum Continuous } \\
\text { Charge }\end{array}$ & $1.35 \mathrm{~A}(1 \mathrm{C})$ & $10 \mathrm{~A}(4 \mathrm{C})$ \\
Cell Weight & $26.84 \mathrm{~g}$ & $74.34 \mathrm{~g}$ \\
Cell Geometry & Prismatic & Cylindrical \\
Internal Resistance & - & $10 \mathrm{~m} \Omega$ \\
Country & Korea & USA \\
(10 A,1s ) & $3.7 \mathrm{~V}$ & $3.3 \mathrm{~V}$ \\
Nominal Voltage & $2.75 \mathrm{~V}$ & $2 \mathrm{~V}$ \\
Discharge Cut-off Voltage & $4.2 \mathrm{~V}$ & $3.6 \mathrm{~V}$ \\
Max. Charging Voltage & $\geq 300 \mathrm{cycles}$ & $1000 \mathrm{cycles}$ \\
Cycle Life & -10 to $50^{\circ} \mathrm{C}$ & -30 to $55^{\circ} \mathrm{C}$ \\
Operating Temperature & $124 \mathrm{~m} \Omega$ & $6 \mathrm{~m} \Omega$ \\
Internal Impedance $(1 \mathrm{kHz})$ & Mobile & ElectricVehicles \\
Applications & Phones & \\
\hline \hline
\end{tabular}

\subsection{Range of frequency sweep}

In Fig.1, the EIS spectrum shows the response due to the processes that take place inside the battery, such as electrode processes, electron and ion transport, the inductive process, the diffusion process, etc. These processes have different time constants and are therefore activated at different AC frequencies. When conducted over a wide range of frequencies, impedance spectroscopy can be used to identify and quantify the impedance associated with these processes [64].

Thus, the range of the frequency sweep must be such that all the battery processes are shown in the EIS spectrum [43]. The inductive behavior at high frequency can originate from the measuring equipment and this behavior can be considered as a systematic error which is not detected by the $\mathrm{K}-\mathrm{K}$ 
relations [65]. However, there are correction methods to subtract this error. The method proposed in this paper employs the inductive section to establish the upper limit of the frequency sweep.

Furthermore, the experiment should be carried out in a short time because, although the experiments are tested under AC current, if the battery is under charge or discharge for a long time, this could modify its SOC.

The reason for using a specific range of frequency sweep in an EIS test is not explained in previous studies [66], [67], [68]. Depending on the battery, a different range of frequency sweep is required to show the different sections in Fig. 1.

In the proposed method, the chosen range of frequency sweep will be the one whose EIS spectrum shows all the characteristic processes and does not have noise. Moreover, the time to carry out the experiment should be as short as possible so as not to change the battery SOC. If necessary, K$\mathrm{K}$ relations can be used to confirm the selected frequency sweep.

\subsection{Measured points per decade.}

The number of points per decade defines the data density in an impedance spectrum. The data are spaced logarithmically and the number of points is the same in all decades. A plot with a high number of points per decade may require an unnecessarily long time to perform the test, while information may be lost if the plot has a low number of points per decade. Ten points per decade have been used in several studies [69], [47], [70], but none of these papers justifies why ten is the most suitable number.

In the method proposed here, the number of points per decade must meet the following requirements: a) the plot should clearly show all the sections described in Fig. 1; b) there should be no loss of information; and c) the time to obtain the plot should not be excessive. Among all the numbers that meet these conditions, the one with the best goodness-of-fit value of K-K will be chosen.

\subsection{Length of the pause time after a change in the SOC}

If an EIS test is carried out after a change in the battery SOC, it should be borne in mind that the battery needs time to reach equilibrium after this change. Lengths of the pause time from 15 to 90 minutes after a change in the SOC are recommended in some studies [47].

In the proposed method, several preliminary tests are performed with different length of pause time to determine the time required for the battery to stabilize after a SOC change. When the Nyquist plots of two consecutive preliminary tests are equal, the required time to reach equilibrium after the SOC change is obtained. Then, $\mathrm{K}-\mathrm{K}$ relations are used to confirm the selected pause time.

\subsection{Length of the pause time after a change in the ambient temperature}

If an EIS test is carried out after a change in the ambient temperature, the battery will need time to reach equilibrium after this change.
In the proposed method, several preliminary tests are performed with different lengths of the pause time to determine the time required for the battery to reach equilibrium after a change in the ambient temperature. When the Nyquist plots of two consecutive preliminary tests are equal, the required time to stabilize after the change in the ambient temperature is obtained. Then, $\mathrm{K}-\mathrm{K}$ relations are used to confirm the selected pause time.

\section{Experimental Results}

Preliminary test were carried out at $23^{\circ} \mathrm{C}$ and $50 \%$ SOC, except when determining the length of the pause time after a change in temperature and a change in the SOC.

\subsection{AC current amplitude}

All tests to determine the AC current were performed using a frequency sweep ranging from $10^{-1} \mathrm{~Hz}$ to $10^{5} \mathrm{~Hz}$.

The upper limit imposed by the Gamry Reference 3000 is $1.8 \mathrm{~A} \mathrm{rms}$. For the battery voltage not to exceed $25 \mathrm{mV} \mathrm{rms}$, which corresponds to an amplitude of $35 \mathrm{mV}$, the maximum current in the case of Cell 1 is $0.2 \mathrm{~A} \mathrm{rms}$, as its internal impedance is $130 \mathrm{~m} \Omega$. Given that the upper limit imposed by the galvanostat is higher than the upper limit imposed by the cell, the limit imposed by the cell is chosen. The internal impedance of Cell 2 is $6 \mathrm{~m} \Omega$; hence the allowed maximum current is $4.16 \mathrm{~A} \mathrm{rms}$. In this case, as the selected upper limit of the galvanostat (1.8 A rms) is lower, this value is chosen.

The lower limit imposed by the maximum frequency obtained in the test will be $5 \mu \mathrm{A}$ if the maximum frequency is $10^{5} \mathrm{~Hz}$ and $510^{-1} \mu \mathrm{A}$ if the maximum frequency is $10^{4} \mathrm{~Hz}$. Both currents are higher than $1 \mathrm{nA}$, the lower limit imposed by the galvanostat [71].

However, after several tests to obtain a noise-free Nyquist plot, the necessary minimum current is $3.910^{-3} \mathrm{~A}$ rms for Cell 1 and $410^{-2} \mathrm{~A}$ rms for Cell 2. Both values are higher than 5 $\mu \mathrm{A}$, the lower limit imposed by a maximum frequency of $10^{5}$ $\mathrm{Hz}$

For Cell 1, it can be seen in Fig. 7a that the Nyquist plot corresponding to $3.910^{-4} \mathrm{~A} \mathrm{rms}$, which falls outside the range, has noise. The Nyquist plot corresponding to $1.8 \mathrm{~A}$ rms, which also falls outside the range, is noise-free, but does not show all the processes that take place in the battery. In this case, this value must be discarded, as stated in Section IV. Thus, the AC current for Cell 1 ranges from $3.910^{-3} \mathrm{~A}$ rms to $0.2 \mathrm{~A} \mathrm{rms}$, while for Cell 2, it ranges from $410^{-2} \mathrm{~A}$ rms to $1.8 \mathrm{~A}$ rms.

The diffusion process is not shown. However, even currents within the $3.910^{-3} \mathrm{~A} \mathrm{rms}$ to $0.2 \mathrm{~A} \mathrm{rms}$ range may not be suitable. For instance, the Nyquist plot corresponding to 8.9 $10^{3} \mathrm{~A}$ rms, also shown in Fig. 7a, is not a suitable value even though it is noise-free, because it does not show the diffusion process.

Fig. 7b shows some Nyquist plots corresponding to currents within the $3.910^{-3} \mathrm{~A}$ rms to $0.2 \mathrm{~A}$ rms range that may be suitable. Not all the possible currents tested are represented because they overlap. Apparently there is no difference between them; all are noise-free and show all the battery 
processes. K-K relations are applied to choose the optimal current. The best current value is the one with a Nyquist plot that has the smallest goodness of fit of K-K; see Table II. The best current value is thus $3.910^{-3} \mathrm{~A}$ rms.

The left side of Table II shows the goodness of fit of K-K for current values falling within and outside the $3.910^{-3} \mathrm{~A} \mathrm{rms}$ to $0.2 \mathrm{~A}$ rms range. It can be seen that not only do the current values outside the $3.910^{-3} \mathrm{~A}$ rms to $0.2 \mathrm{~A}$ rms range have a poorer goodness of fit of K-K than the selected current value, but they also have a poorer goodness of fit of K-K than all the other currents within the range.

The best current value for Cell 2 is chosen via the same procedure as for Cell 1. Fig. 8 shows three Nyquist plots of Cell 2. Unlike Cell 1, not all the processes are clearly shown in this case due to the characteristics of Cell 2: the time constants of some processes are similar and the activating

TABLE II

GOODNESS OF FIT OF K-K FOR THE TESTED AC CURRENTS

\begin{tabular}{ccrc}
\hline \multicolumn{2}{c}{ Cell 1 } & \multicolumn{2}{c}{ Cell 2} \\
AC $(\mathrm{A})$ & \multicolumn{1}{c}{ K-K } & AC $(\mathrm{A})$ & \multicolumn{1}{c}{$\mathrm{K}-\mathrm{K}$} \\
\hline $3.910^{-04}$ & $2.1010^{-04}$ & $410^{-03}$ & $2.70810^{-04}$ \\
$3.910^{-03}$ & $4.510^{-06}$ & $410^{-02}$ & $2.59010^{-04}$ \\
$8.910^{-03}$ & $1.0410^{-06}$ & $110^{-01}$ & $5.76910^{-07}$ \\
$3.910^{-02}$ & $8.0510^{-08}$ & $1.510^{-01}$ & $6.79910^{-07}$ \\
$8.910^{-02}$ & $2.7810^{-07}$ & $510^{-01}$ & $3.86310^{-07}$ \\
$3.910^{-02}$ & $7.6010^{-07}$ & $8.310^{-01}$ & $7.12610^{-07}$ \\
$8.910^{-03}$ & $9.7610^{-06}$ & $110^{00}$ & $9.25710^{-09}$ \\
1.8 & $3.6710^{-05}$ & $1.510^{00}$ & $1.34710^{-06}$ \\
& & 1.8 & $1.90310^{-06}$ \\
\hline \hline
\end{tabular}

frequencies of those processes are very close. One of the plots corresponds to $410^{-3} \mathrm{~A}$ rms, a value falling outside the selected $410^{-2} \mathrm{~A}$ rms to $1.810^{00} \mathrm{~A}$ rms range. As expected, it is not noise-free. The other two plots correspond to current values falling within the $410^{-2} \mathrm{~A}$ rms to $1.810^{00} \mathrm{~A}$ rms range.

The right side of Table II shows the goodness of fit of $\mathrm{K}-\mathrm{K}$ of all the tested currents for Cell 2. The optimal current is $1 \mathrm{~A}$ rms because it is noise-free, the corresponding plot shows the processes as clearly as possible and it has the smallest goodness of fit of K-K. For Cell 2, as for Cell 1, current values falling outside the range also have a poorer goodness of fit of $\mathrm{K}-\mathrm{K}$ than currents falling within the range.

\subsection{Range of frequency sweep}

Due to problems of convergence, galvanostats usually recommend performing the frequency sweep from the highest to the lowest frequency. The Gamry Reference 3000 has apparently overcome this problem: when two sweeps with the limit frequencies are performed, one from the highest to the lowest frequency and the other from the lowest to the highest frequency, the resulting Nyquist plots overlap. However, when the sweep is carried out from the highest to the lowest frequency, the goodness of fit of $\mathrm{K}-\mathrm{K}$ is better. Thus, the sweeps are always performed from the highest to the lowest frequency [34].
Fig. 9 shows the Nyquist plots corresponding to different frequency sweeps for Cell 1, while the left side of Table III. shows their goodness of fit. Although the frequency sweep from $10^{5} \mathrm{~Hz}$ to $10^{-4} \mathrm{~Hz}$ shows all the possible information of a Nyquist plot, it is discarded because the frequency sweep reaches very low frequencies. During the sweep, the EIS could remain in the half cycle discharge mode for a long time and unexpected reactions could take place. Furthermore, the SOC could change when the charge reaches the half cycle. The sweeps that finish at $10^{-1} \mathrm{~Hz}$ are discarded because they do not show the diffusion process of the battery. The sweeps that start at $10^{4} \mathrm{~Hz}$ are discarded because the inductive behavior is barely shown. The frequency sweep from $10^{5} \mathrm{~Hz}$ to $10^{-2} \mathrm{~Hz}$ is the most suitable frequency sweep: it does not take a long time to perform the test and all the processes are shown.
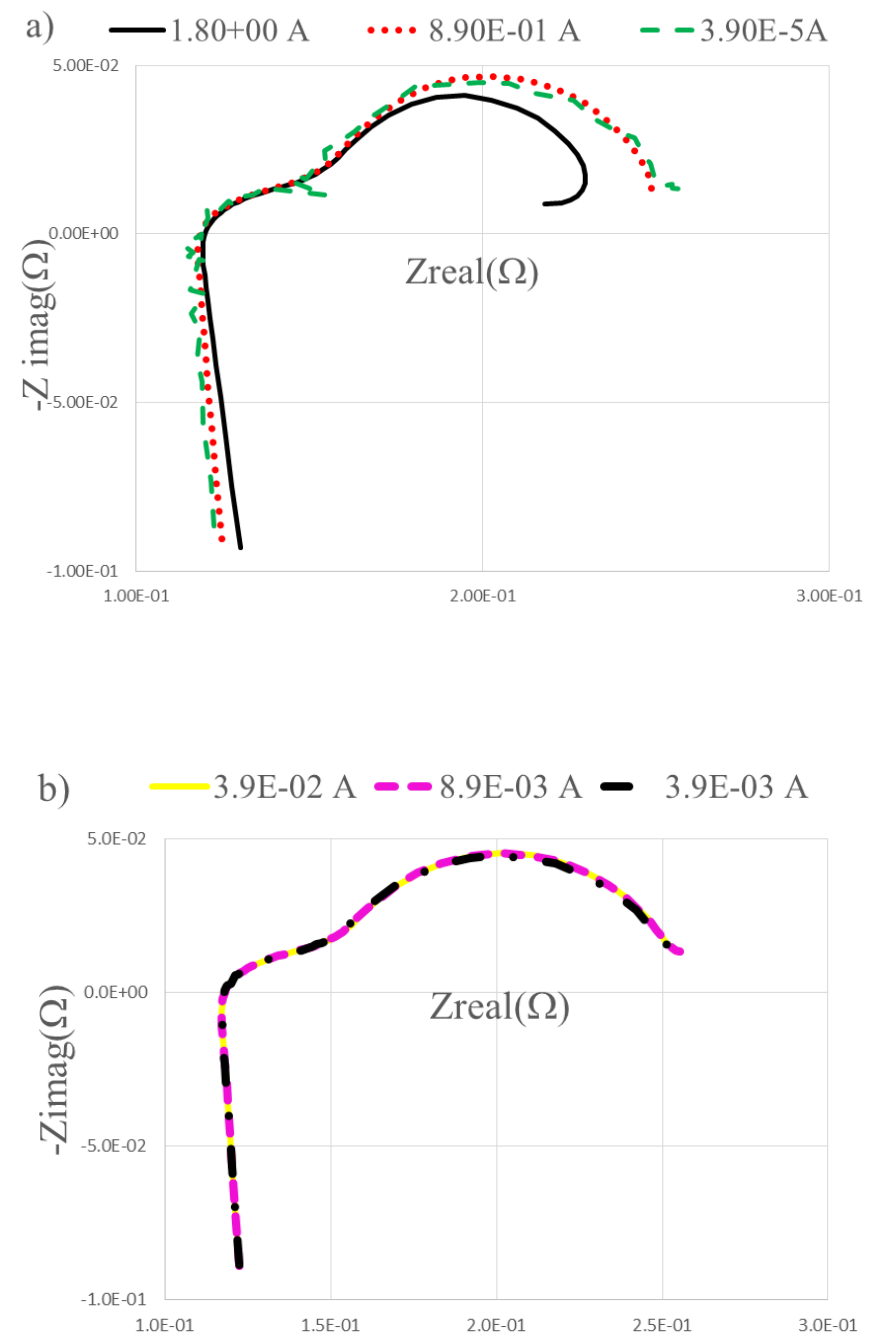

Figure 7: a) Unsuitable AC currents (in Amps rms) tested in Cell 1, b) The best and two others suitable AC currents.

Fig. 10 shows the Nyquist plots corresponding to different frequency sweeps for Cell 2, while the right side of Table III. shows their goodness of fit. All the tested frequency sweeps for Cell 2 show the same battery processes. The sweeps starting at $10^{4} \mathrm{~Hz}$ allow the inductive behavior to be seen, so it is not necessary to start the sweep at $10^{5} \mathrm{~Hz}$. The frequency 
sweeps that finish at $10^{-3} \mathrm{~Hz}$ show a long section of the diffusion process. The frequency sweeps starting at $10^{-2} \mathrm{~Hz}$ and $10^{-1} \mathrm{~Hz}$ also allow the diffusion process to be seen, so a sweep finishing at $10^{-1} \mathrm{~Hz}$ is sufficient. Moreover, the frequency sweep from $10^{4} \mathrm{~Hz}$ to $10^{-1} \mathrm{~Hz}$ is the best because its corresponding Nyquist plot has the best goodness of fit of $\mathrm{K}$ K.

\subsection{Measured points per decade}

Figs. 11 and 12 show the Nyquist plots corresponding to different numbers of measured points per decade tested for Cell 1 and Cell 2, respectively. As 5 points per decade are few points and the information provided by the plots is not sufficient, this value is discarded. With 10 and 15 points per decade, the plots are clearly defined and there is no loss of information.

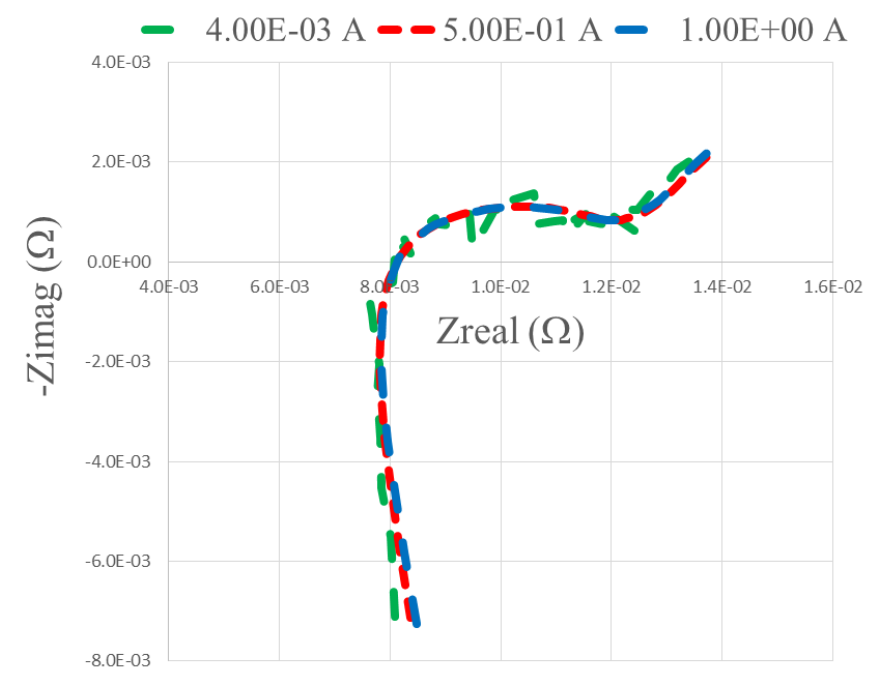

Figure 8. Some of AC currents (in Amps rms) tested in Cell 2.

Table IV shows the goodness of fit of $\mathrm{K}-\mathrm{K}$ for the plots corresponding to different numbers of points per decade. As the plots corresponding to 10 points per decade have the best goodness of fit of $\mathrm{K}-\mathrm{K}$, this value is chosen.

\subsection{Length of the pause time after a change in the SOC}

The SOC was changed from $50 \%$ to $40 \%$ for Cells 1 and 2 in these preliminary tests.

Fig. 13 shows the plots corresponding to some of the tested lengths of the pause time after the change in the SOC in Cell 1, while the left side of Table $\mathbf{V}$. shows their goodness of fit parameters. When this time is greater than 180 minutes, all the plots overlap, hence this is the time required for the battery to stabilize. As the goodness-of-fit parameters for pause times ranging from 180 minutes to the longest one are of the same order of magnitude, 180 minutes is chosen as it is the shortest pause time.

Fig. 14 shows the plots corresponding to some of the tested lengths of the pause time after a change in the SOC in Cell 2. In this case, the differences are only measurable in the diffusion section. All the Nyquist plots overlap after a change in SOC when the pause time is equal to or greater than 120 minutes.

The right side of Table $\mathbf{V}$ shows the goodness of fit of $\mathrm{K}-\mathrm{K}$ for the tested lengths of the pause time. The K-K parameters are of the same order of magnitude for a pause time ranging from 150 minutes to 48 hours and of a higher order for a pause time of 120 minutes. Thus, 120 minutes is discarded and 150 minutes is selected as the pause time

TABLE III GOODNESS OF FIT OF K-K FOR THE TESTED FREQUENCY SWEEPS

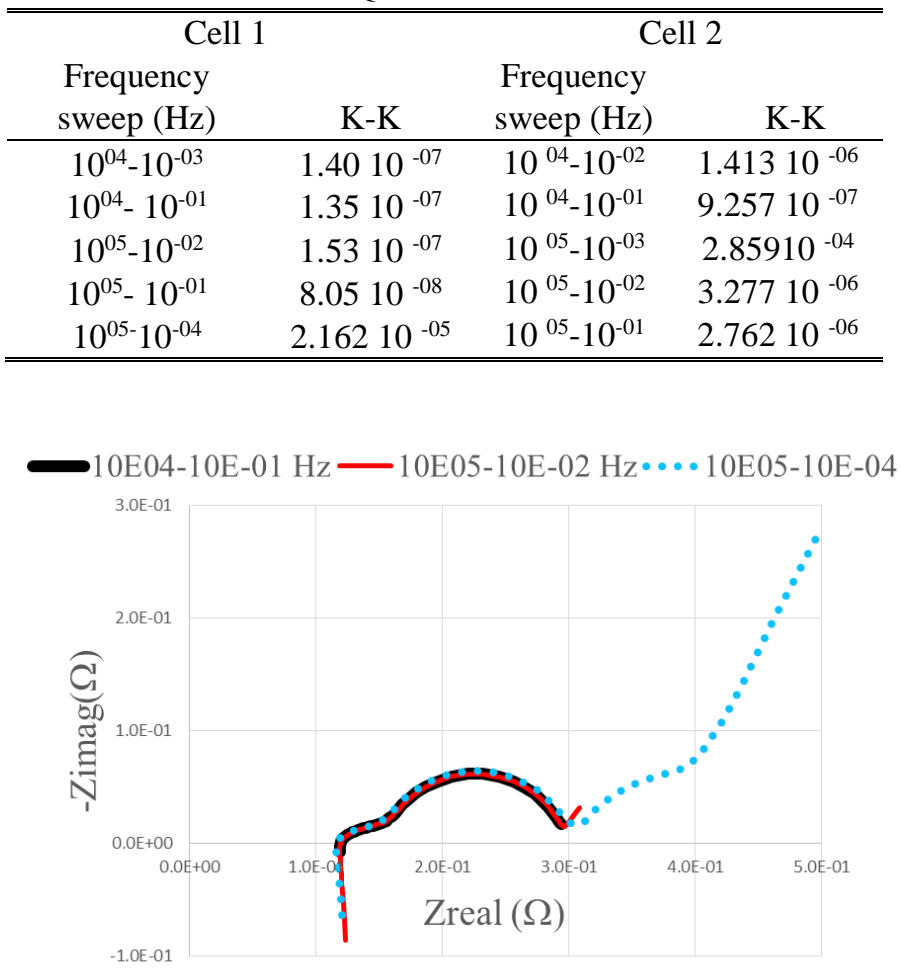

Figure 9: Frequency sweeps (in $\mathrm{Hz}$ ) tested in Cell 1.

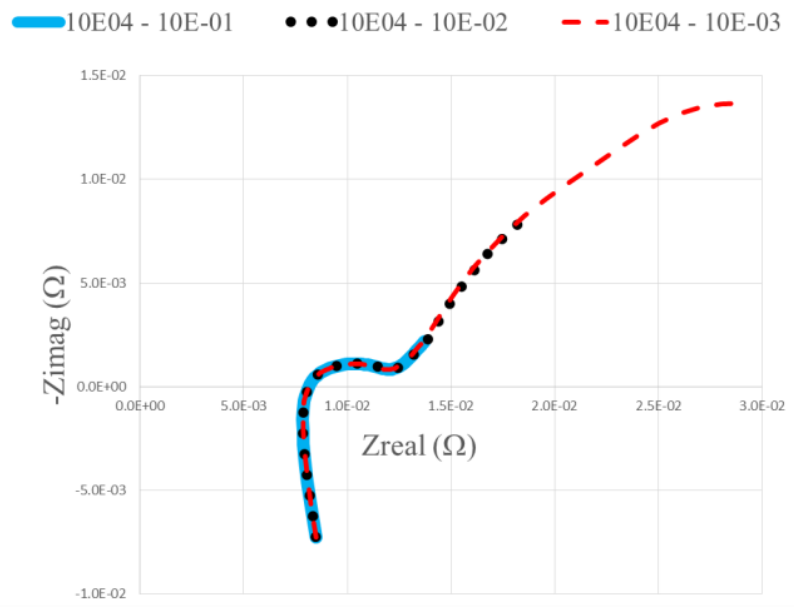

Figure 10: Frequency sweeps (in Hz) tested in Cell 2. 
TABLE IV GOODNESS OF FIT OF THE TESTED P/D

\begin{tabular}{cccc}
\hline \hline & Cell 1 & \multicolumn{2}{c}{ Cell 2 } \\
$\mathrm{p} / \mathrm{d}$ & $\mathrm{K}-\mathrm{K}$ & $\mathrm{p} / \mathrm{d}$ & $\mathrm{K}-\mathrm{K}$ \\
\hline 5 & $2.76210^{-06}$ & 5 & $2.66010^{-06}$ \\
10 & $9.25710^{-07}$ & 10 & $9.25710^{-07}$ \\
15 & $1.41310^{-06}$ & 15 & $1.81010^{-06}$ \\
\hline \hline
\end{tabular}

\subsection{Length of the pause time after a change in the ambient} temperature

In these preliminary tests, a change from $12^{\circ} \mathrm{C}$ to $0^{\circ} \mathrm{C}$ was carried out for Cell 1 and a change from $23^{\circ} \mathrm{C}$ to $10^{\circ} \mathrm{C}$ for Cell 2. Figs.15 and 16 show the Nyquist plots corresponding to different tested lengths of the pause time after the change in the ambient temperature for Cells 1 and 2, respectively. There are no differences in the Nyquist plot between the plots obtained 0 minutes after the temperature change and those obtained after several hours.

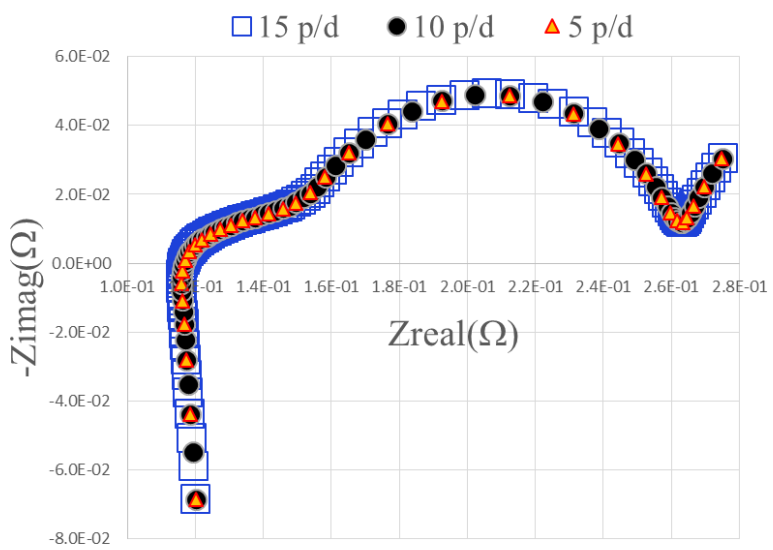

Figure 11: Points per decade tested in Cell 1

TABLE V GOODNESS OF FIT OF K-K FOR LENGTHS OF THE PAUSE TIME AFTER A CHANGE IN SOC

\begin{tabular}{cccc}
\hline & Cell 1 & \multicolumn{2}{c}{ Cell 2 } \\
Time (min) & K-K & Time (min) & K-K \\
\hline 0 & $1.30910^{-04}$ & 0 & $1.72010^{-06}$ \\
30 & $1.37910^{-07}$ & 30 & $1.13310^{-06}$ \\
60 & $2.25910^{-07}$ & 60 & $1.19310^{-06}$ \\
90 & $2.10110^{-07}$ & 90 & $1.04010^{-06}$ \\
120 & $2.08210^{-07}$ & 120 & $1.02910^{-06}$ \\
150 & $1.34910^{-07}$ & 150 & $9.83910^{-07}$ \\
180 & $2.07710^{-07}$ & 180 & $9.02910^{-07}$ \\
210 & $2.38110^{-07}$ & 210 & $8.54610^{-07}$ \\
1080 & $1.91710^{-07}$ & 240 & $8.07810^{-07}$ \\
& & $>2880$ & $8.16810^{-07}$ \\
\hline \hline
\end{tabular}

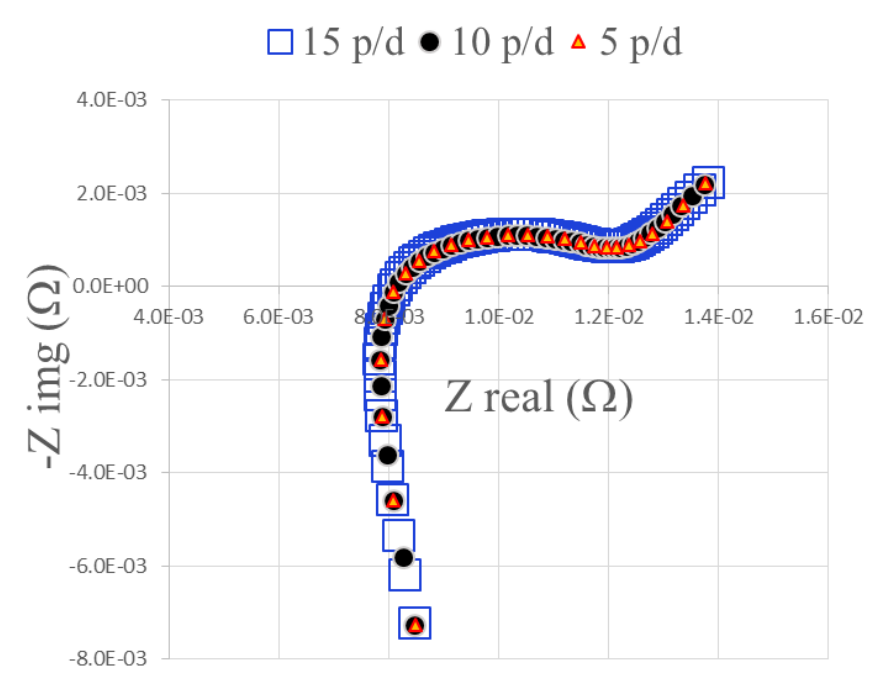

Figure 12. Points per decade tested in Cell 2

TABLE VI GOODNESS OF FIT OF K-K FOR LENGTHS OF THE PAUSE TIME AFTER A CHANGE IN TEMPERATURE

\begin{tabular}{cccc}
\hline \hline & Cell 1 & \multicolumn{2}{c}{ Cell 2 } \\
\hline Time (min) & K-K & Time (min) & K-K \\
0 & $763.610^{-09}$ & 0 & $96910^{-09}$ \\
60 & $64.6110^{-09}$ & 30 & $828.210^{-09}$ \\
90 & $97.1410^{-09}$ & 60 & $897.210^{-09}$ \\
120 & $113.410^{-09}$ & 90 & $941.910^{-09}$ \\
180 & $64.6110^{-09}$ & 120 & $780.310^{-09}$ \\
& & 150 & $909.810^{-09}$ \\
& & 180 & $819.510^{-09}$ \\
& & 210 & $967.710^{-09}$ \\
& & 240 & $863.210^{-09}$ \\
& & $>2880$ & $815.110^{-09}$ \\
\hline \hline
\end{tabular}

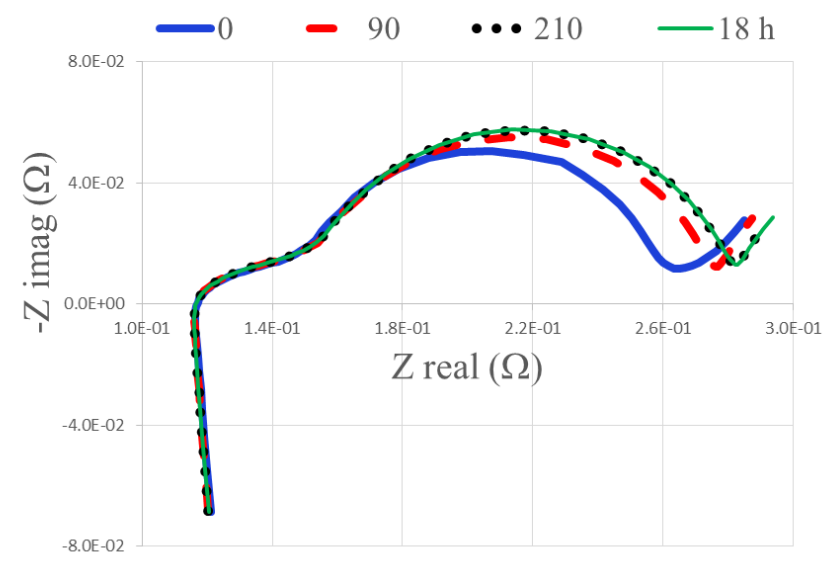

Figure 13. Some of the lengths of the pause time (in minutes) after a change in the SOC in Cell 1. 


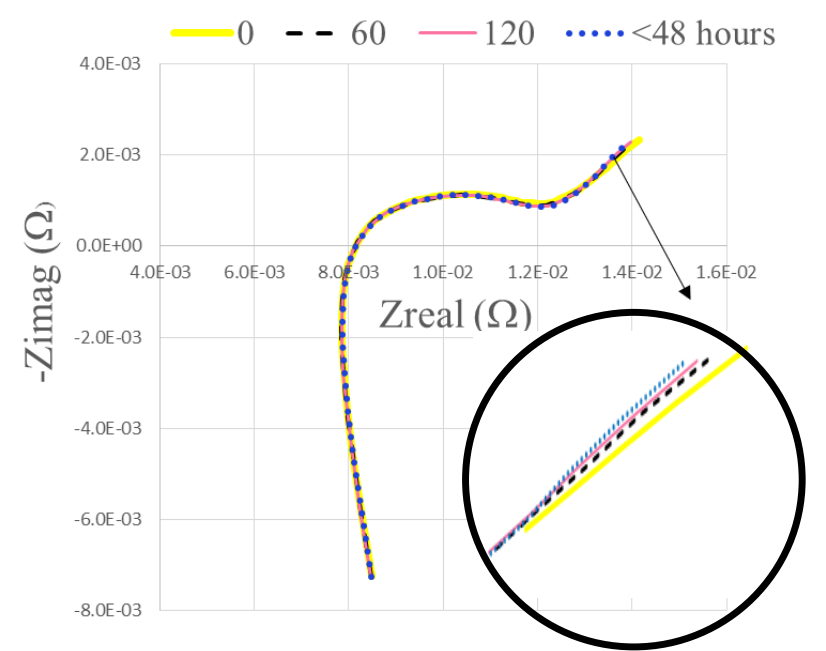

Figure 14. Some of the tested lengths of pause time (in minutes) after a change in the SOC in Cell 2

The values of the goodness of fit of K-K in both cells are of the same order of magnitude for all pause times (from 0 minutes to 48 hours); see Table VI.

Taking into account its constructive features [72], it was estimated that Cell 2 would reach thermal equilibrium in approximately 70 minutes after a sudden change in the ambient temperature from $23^{\circ} \mathrm{C}$ to $10^{\circ} \mathrm{C}$ [73]. However, the time required for batteries to reach equilibrium could be higher, depending on the size of batteries [47].

In our case, however, the change in the ambient temperature from $23^{\circ} \mathrm{C}$ to $10^{\circ} \mathrm{C}$ is not instant; it takes several hours. Thus, equilibrium in the cell is reached when the chamber reaches $10^{\circ} \mathrm{C}$. Hence, no pause time is needed to carry out EIS tests after a change in the ambient temperature

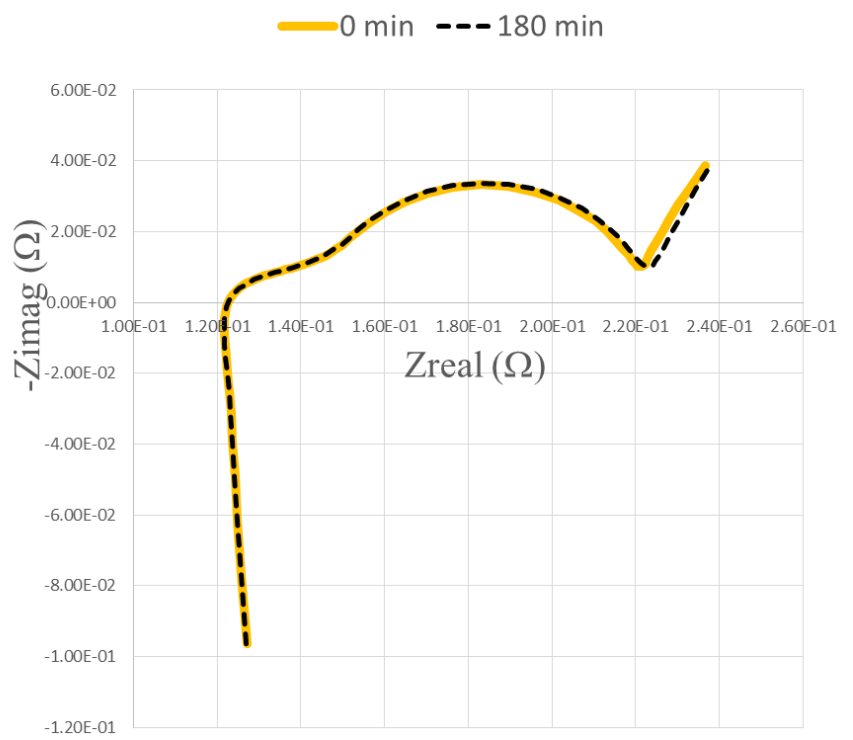

Figure 15. The tested lengths of pause time (in minutes) after a change in temperature from $12^{\circ} \mathrm{C}$ to $0^{\circ} \mathrm{C}$ in Cell 1 .

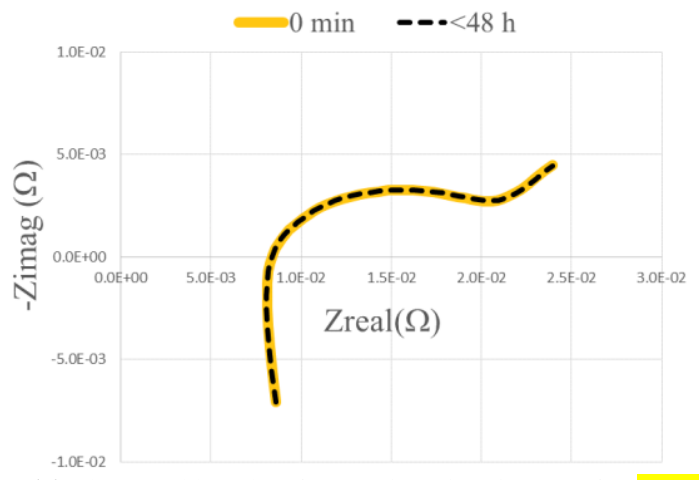

Figure 16: The tested lengths of pause time (in minutes) after a change in temperature from $23^{\circ} \mathrm{C}$ to $10^{\circ} \mathrm{C}$ in Cell 2 .

\section{Conclusions}

A method to determine and optimize the necessary parameters to perform useful EIS tests has been presented in this paper. To the best of our knowledge, a similar method has not been previously reported in the scientific literature. Some general recommendations can be found, though no systematic method like the one presented here.

First, the method combines several criteria to select a set of possible suitable values for each parameter. Each parameter has its own criteria. Some of these criteria are qualitative (e.g. the Nyquist plot should show all the battery processes) while others are quantitative (e.g. the Nyquist plot should be noisefree). The method then employs a quantitative criterion, K-K relations, to select the best value from the set of possible values for the parameter. This second step is common to all the parameters. When the value of a parameter is determined, this value is used to obtain the next parameter.

The proposed method allows saving time and ensures that the information obtained from the EIS tests will be useful. The method has been tested on two Li-ion batteries with different characteristics in terms of chemistry, capacity, voltages, geometry and applications. Experimental results show how to apply the determination procedure and confirm the validity of the method. The method could be extended to any other battery technology.

\section{Acknowledgements}

This work is partly supported by the Science and Innovation Spanish Ministry and FEDER under the Projects DPI2013-046541-R, TIN2014-56967-R, TEC2016-80700-R (AEI/FEDER, UE) and by the Principality of Asturias Government under Project FC- 15-GRUPIN14-073.

\section{REFERENCES}

[1] C.T. Cherian, M. Zheng, M. V. Reddy, B.V.R. Chowdari, C.H. Sow, $\mathrm{Zn} 2 \mathrm{SnO} 4$ nanowires versus nanoplates: Electrochemical performance and morphological evolution during Li-cycling, ACS Appl. Mater. Interfaces. 5 (2013) 6054-6060. doi:10.1021/am400802j.

[2] D. Wang, F. Yang, K. Tsui, Q. Zhou, S.J. Bae, Remaining Useful Life Prediction of Lithium-Ion Batteries Based on Spherical Cubature Particle Filter, IEEE Trans. Instrum. Meas. 65 (2016) 110. doi:10.1109/TIM.2016.2534258.

[3] X. Hong, N. Li, Q. Kong, G. Liu, M. Ho, Local cell temperature 
monitoring for aluminum shell lithium-ion battery based on electrical resistance tomography, Measurement. 86 (2016) 227-238. doi:10.1016/j.measurement.2016.02.039.

[4] G. Yang, C. Leitão, Y. Li, J. Pinto, X. Jiang, Real-time temperature measurement with fiber Bragg sensors in lithium batteries for safety usage, Meas. J. Int. Meas. Confed. 46 (2013) 3166-3172. doi:10.1016/j.measurement.2013.05.027.

[5] M. Landi, G. Gross, Measurement techniques for online battery state of health estimation in vehicle-to-grid applications, IEEE Trans. Instrum. Meas. 63 (2014) 1224-1234. doi:10.1109/TIM.2013.2292318.

[6] M.V. Reddy, H.Y. Cheng, J.H. Tham, C.Y. Yuan, H.L. Goh, B.V.R.

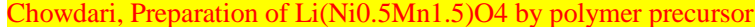
method and its electrochemical properties, Electrochim. Acta. 62 (2012) 269-275. doi:10.1016/j.electacta.2011.12.029.

[7] A. Vadivel Murugan, M. V. Reddy, G. Campet, K. Vijayamohanan, Cyclic voltammetry, electrochemical impedance and ex situ X-ray diffraction studies of electrochemical insertion and deinsertion of lithium ion into nanostructured organic-inorganic poly $(3,4$ ethylenedioxythiophene) based hybrids, J. Electroanal. Chem. 603 (2007) 287-296. doi:10.1016/j.jelechem.2007.02.013.

[8] M. V. Reddy, R. Jose, A. Le Viet, K.I. Ozoemena, B.V.R. Chowdari, S. Ramakrishna, Studies on the lithium ion diffusion coefficients of electrospun $\mathrm{Nb} 2 \mathrm{O} 5$ nanostructures using galvanostatic intermittent titration and electrochemical impedance spectroscopy, Electrochim. Acta. 128 (2013) 1-13. doi:10.1016/j.electacta.2013.10.003.

[9] W. Waag, S. Käbitz, D.U. Sauer, Application-specific parameterization of reduced order equivalent circuit battery models for improved accuracy at dynamic load, Meas. J. Int. Meas. Confed. 46 (2013) 4085-4093. doi:10.1016/j.measurement.2013.07.025.

[10] P. a Lindahl, M. a Cornachione, S.R. Shaw, A Time-Domain Least Squares Approach to Electrochemical Impedance Spectroscopy, Ieee Trans. Instrum. Meas. 61 (2012) 3303-3311. doi:10.1109/tim.2012.2210457.

[11] M. Prabu, M. V. Reddy, S. Selvasekarapandian, G.V.S. Rao, B.V.R. Chowdari, Synthesis, impedance and electrochemical studies of lithium iron fluorophosphate, LiFePO4F cathode, Electrochim. Acta. 85 (2012) 572-578. doi:10.1016/j.electacta.2012.08.073.

[12] A. Terbouche, S. Lameche, C. Ait-Ramdane-Terbouche, D. Guerniche, D. Lerari, K. Bachari, D. Hauchard, A new electrochemical sensor based on carbon paste electrode/Ru(III) complex for determination of nitrite: Electrochemical impedance and cyclic voltammetry measurements, Measurement. (2016). doi:10.1016/j.measurement.2016.06.034.

[13] H. Shih, T. Lo, Electrochemical Impedance Spectroscopy for Battery Research and Development, Solatron, Hampshire, UK, 1996. Cortech Corporation. CA, Tech. Rep, 31(9-11)

[14] M. Itagaki, N. Kobari, S. Yotsuda, K. Watanabe, S. Kinoshita, M. $\mathrm{Ue}, \mathrm{LiCoO} 2$ electrode/electrolyte interface of Li-ion rechargeable batteries investigated by in situ electrochemical impedance spectroscopy, J. Power Sources. 148 (2005) 78-84. doi:10.1016/j.jpowsour.2005.02.007.

[15] J. Hoja, G. Lentka, Method using square-pulse excitation for highimpedance spectroscopy of anticorrosion coatings, IEEE Trans. Instrum. Meas. 60 (2011) 957-964. doi:10.1109/TIM.2010.2060219.

[16] A. Christensen, A. Adebusuyi, Using on-board electrochemical impedance spectroscopy in battery management systems, in: 2013 World Electr. Veh. Symp. Exhib., IEEE, Barcelona, 2013: pp. 1-7. doi:10.1109/EVS.2013.6914969.

[17] L. Ran, W. Junfeng, L. Gechen, Prediction of State of Charge of Lithium-ion Rechargeable Battery with Electrochemical Impedance Spectroscopy Theory, 2010 5th IEEE Conf. Ind. Electron. Appl. (2010) 684-688. doi:10.1109/ICIEA.2010.5516984.

[18] M. Prabu, S. Selvasekarapandian, M. V. Reddy, B.V.R. Chowdari, Impedance studies on the 5-V cathode material, LiCoPO 4, J. Solid State Electrochem. 16 (2012) 1833-1839. doi:10.1007/s10008-012 1670-2.

[19] M. V. Reddy, G. V. Subba Rao, B.V.R. Chowdari, Long-term cycling studies on $4 \mathrm{~V}$-cathode, lithium vanadium fluorophosphate, J. Power Sources. 195 (2010) 5768-5774 doi:10.1016/j.jpowsour.2010.03.032.

[20] M. V. Reddy, G. V. Subba Rao, B.V.R. Chowdari, Nano(V1/2Sb1/2Sn)O4: a high capacity, high rate anode material for $\mathrm{Li}$ - ion batteries, J. Mater. Chem. 21 (2011) 10003. doi:10.1039/c0jm04140h.

[21] M. Prabu, M. V. Reddy, S. Selvasekarapandian, G. V. Subba Rao, B.V.R. Chowdari, (Li, Al)-co-doped spinel, Li(Li0.1 Al0.1Mn 1.8)O4 as high performance cathode for lithium ion batteries, Electrochim. Acta. 88 (2013) 745-755. doi:10.1016/j.electacta.2012.10.011.

[22] M. V Reddy, A. Sakunthala, S. Selvashekarapandian, B.V.R. Chowdari, Preparation, Comparative Energy Storage Properties, and Impedance Spectroscopy Studies of Environmentally Friendly Cathode, Li(MMn11/6)O4 (M = Mn1/6,Co1/6, (Co1/12Cr1/12)), 4 (2013). doi:dx.doi.org/10.1021/jp309180k.

[23] A. Sakunthala, M. V. Reddy, S. Selvasekarapandian, B.V.R. Chowdari, P.C. Selvin, Preparation, characterization, and electrochemical performance of lithium trivanadate rods by a surfactant-assisted polymer precursor method for lithium batteries, J. Phys. Chem. C. 114 (2010) 8099-8107. doi:10.1021/jp1005692.

[24] P. Nithyadharseni, M. V. Reddy, B. Nalini, M. Kalpana, B.V.R. Chowdari, Sn-Based intermetallic alloy anode materials for the application of lithium ion batteries, Electrochim. Acta. 161 (2015) 261-268. doi:10.1016/j.electacta.2015.02.057.

[25] B. Das, M. V. Reddy, C. Krishnamoorthi, S. Tripathy, R. Mahendiran, G.V.S. Rao, B.V.R. Chowdari, Carbothermal synthesis, spectral and magnetic characterization and Li-cyclability of the Mo-cluster compounds, LiYMo3O8 and Mn2Mo3O8, Electrochim. Acta. 54 (2009) 3360-3373. doi:10.1016/j.electacta.2008.12.049.

[26] M. V. Reddy, S. Madhavi, G. V. Subba Rao, B.V.R. Chowdari, Metal oxyfluorides TiOF2 and $\mathrm{NbO} 2 \mathrm{~F}$ as anodes for $\mathrm{Li}$-ion batteries, J. Power Sources. 162 (2006) 1312-1321. doi:10.1016/j.jpowsour.2006.08.020.

[27] B. Das, M. V. Reddy, G. V. Subba Rao, B.V.R. Chowdari, Nanophase tin hollandites, $\mathrm{K}_{2}\left(\mathrm{M}_{2} \mathrm{Sn}_{6}\right) \mathrm{O}_{16}(\mathrm{M}=\mathrm{Co}$, In) as anodes for Li-ion batteries, J. Mater. Chem. 21 (2011) 1171-1180. doi:10.1039/C0JM02098B

[28] S. Petnikota, S.K. Marka, A. Banerjee, M. V. Reddy, V.V.S.S. Srikanth, B.V.R. Chowdari, Graphenothermal reduction synthesis of "exfoliated graphene oxide/iron (II) oxide" composite for anode application in lithium ion batteries, J. Power Sources. 293 (2015) 253-263. doi:10.1016/j.jpowsour.2015.05.075.

[29] M. V Reddy, B.L. Wei Wen, K.P. Loh, B.V.R. Chowdari, Energy Storage Studies on InVO4 as High Performance Anode Material for Li-Ion Batteries., ACS Appl. Mater. Interfaces. 5 (2013) 7777-85. doi:10.1021/am401501a.

[30] F. Nobili, F. Croce, B. Scrosati, R. Marassi, Electronic and Electrochemical Properties of $\mathrm{Li}(\mathrm{x}) \mathrm{Ni}(1-\mathrm{y}) \mathrm{Co}(\mathrm{y}) \mathrm{O} 2$ Cathodes Studied by Impedance, Chem. Mater. (2001) 1642-1646. doi:10.1021/cm000600x.

[31] G. Qiao, Y. Hong, J. Ou, Corrosion monitoring of the RC structures in time domain: Part I. Response analysis of the electrochemical transfer function based on complex function approximation, Measurement. 67 (2015) 78-83. doi:10.1016/j.measurement.2014.12.018

[32] A. Carullo, F. Ferraris, M. Parvis, A. Vallan, E. Angelini, P. Spinelli, Low-cost electrochemical impedance spectroscopy system for corrosion monitoring of metallic antiquities and works of art, IEEE Trans. Instrum. Meas. 49 (2000) 371-375.

doi:10.1109/19.843080.

[33] Kasey, EIS Measurement of a Very Low Impedance Lithium Ion Battery, Gamry Appl. Note. (2011) 1-6. http://www.gamry.com/application-notes/EIS/eis-measurement-ofa-very-low-impedance-lithium-ion-battery/.

[34] G. Instruments, Reference 3000. Potentiostat / Galvanostat / ZRA Operator's Manual, ReVision. (2010).

[35] R. Al Nazer, V. Cattin, P. Granjon, M. Montaru, M. Ranieri, Broadband identification of battery electrical impedance for HEVs, IEEE Trans. Veh. Technol. 62 (2013) 2896-2905. doi:10.1109/TVT.2013.2254140.

[36] K.H. Teoh, C.-S. Lim, S. Ramesh, Lithium ion conduction in corn starch based solid polymer electrolytes, Measurement. 48 (2013) 87-95. doi:10.1016/j.measurement.2013.10.040.

[37] D. Das, F.A. Kamil, S. Agrawal, K. Biswas, S. Das, Fragmental frequency analysis method to estimate electrical cell parameters from bioimpedance study, IEEE Trans. Instrum. Meas. 63 (2014) 1991-2000. doi:10.1109/TIM.2014.2303553. 
[38] M. V Reddy, G.V.S. Rao, B.V.R. Chowdari, Preparation and characterization of $\mathrm{LiNi0} .5 \mathrm{Co} 0.5 \mathrm{O} 2$ and $\mathrm{LiNi} 0.5 \mathrm{Co} 0.4 \mathrm{Al0} .1 \mathrm{O} 2$ by molten salt synthesis for Li ion batteries, J. Phys. Chem. C. 111 (2007) 11712-11720. doi:Doi 10.1021/Jp0676890.

[39] R.C. Ambare, S.R. Bharadwaj, B.J. Lokhande, Spray pyrolysed $\mathrm{Mn}: \mathrm{Co} 3 \mathrm{O} 4$ thin film electrodes via non-aqueous route and their electrochemical parameter measurements, Meas. J. Int. Meas. Confed. 88 (2016) 66-76. doi:10.1016/j.measurement.2016.02.063.

[40] P. Weßkamp, P. Haußmann, J. Melbert, 600-A Test System for Aging Analysis of Automotive Li-Ion Cells With High Resolution and Wide Bandwidth, IEEE Trans. Instrum. Meas. 65 (2016) 1-10. doi:10.1109/TIM.2016.2534379.

[41] M.D. Levi, K. Gamolsky, D. Aurbach, U. Heider, R. Oesten, On electrochemical impedance measurements of $\mathrm{LixCo} 0.2 \mathrm{Ni0} 0.8 \mathrm{O} 2$ and LixNiO2 intercalation electrodes, Electrochim. Acta. 45 (2000) 1781-1789. doi:10.1016/S0013-4686(99)00402-8.

[42] J. Vetter, P. Novák, M.R. Wagner, C. Veit, K.C. Möller, J.O Besenhard, M. Winter, M. Wohlfahrt-Mehrens, C. Vogler, A. Hammouche, Ageing mechanisms in lithium-ion batteries, J. Power Sources. 147 (2005) 269-281. doi:10.1016/j.jpowsour.2005.01.006.

[43] J. Li, E. Murphy, J. Winnick, P.A. Kohl, Studies on the cycle life of commercial lithium ion batteries during rapid charge-discharge cycling, J. Power Sources. 102 (2001) 294-301. doi:10.1016/S03787753(01)00821-7.

[44] E. Barsoukov, J.R. Macdonald, Impedance Spectroscopy, Second Edi, A John Wiley \& Sons, Inc., Publication, New Yersey, 2005. doi:10.1002/0471716243.

[45] G. Dotelli, R. Ferrero, P.G. Stampino, S. Latorrata, Analysis and compensation of PEM fuel cell instabilities in low-frequency EIS measurements, IEEE Trans. Instrum. Meas. 63 (2014) 1693-1700. doi:10.1109/TIM.2013.2297632.

[46] P. Singh, M.A. Quraishi, Corrosion inhibition of mild steel using Novel Bis Schiff's Bases as corrosion inhibitors: Electrochemical and Surface measurement, Measurement. 86 (2016) 114-124. doi:10.1016/j.measurement.2016.02.052.

[47] D. Andre, M. Meiler, K. Steiner, C. Wimmer, T. Soczka-guth, D.U. Sauer, Characterization of high-power lithium-ion batteries by electrochemical impedance spectroscopy . I . Experimental investigation, J. Power Sources. 196 (2011) 5334-5341. doi:10.1016/j.jpowsour.2010.12.102.

[48] D.D. Urquidi-Macdonald, Mirna, Real, Silvia, Macdonald, Application of kramers-kronig transforms in the analysis of electrochemical impedance data: II. transformations in the complex plane., J. Electrochem. Soc. (1986). 20182024.doi:10.1149/1.2108332.

[49] J.S. Toll, Causality and the dispersion relation: Logical foundations, Phys. Rev. 104 (1956) 1760-1770. doi:10.1103/PhysRev.104.1760.

[50] A. H.A. Kramers, Congr. Intern. Fisici., in: 1927: p. Como 2, 545.

[51] H.A. Kramers, Phys. Zeit 30, in: 1929. 522-523.

[52] K.F. Herzfeld, M. Goeppert-Mayer, On the theory of dispersion, Phys. Rev. 49 (1936) 332-339. doi:10.1103/PhysRev.49.332.

[53] H.W. Bode, Network Analysis and Feedback Amplifier Design, in: n.d.

[54] J.M. Esteban, M.E. Orazem, On the Application of the KramersKronig Relations to Evaluate the Consistency of Electrochemical Impedance Data, J. Electrochem. Soc. 138 (1991) 67-76. doi:10.1149/1.2085580.

[55] Orazem, Electrochemical Impedance Spectroscopy, in: Electrochem. Impedance Spectrosc., John Whiley, 2008: pp. 427438.

[56] P. Agarwal, M.E. Orazem, L.H. Garcia-Rubio, The influence of error structure on interpretation of impedance spectra, Electrochim. Acta. 41 (1996) 1017-1022. doi:10.1016/0013-4686(95)00433-5. B. a. Boukamp, A Linear Kronig-Kramers Transform Test for Immittance Data Validation, J. Electrochem. Soc. 142 (1995) 1885. doi:10.1149/1.2044210.

[58] P. Agarwal, M.E. Orazem, L.H. Garcia-Rubio, Measurement Models for Electrochemical Impedance Spectroscopy I . Demonstration of Applicability, J. Electrochem. Soc. 139 (1992) 1917-1927. doi:10.1149/1.2069522.

[59] T. Idaho, E. National, U . S . Department of Energy Vehicle Technologies Program Battery Test Manual For Plug-In Hybrid Electric Vehicles, (2010). http://avt.inl.gov/battery/pdf/PLUG_IN_HYBRID_Manual Rev 2.pdf.
[60] D. Ansean, M. Gonzalez, V.M. Garcia, J.C. Viera, J.C. Anton, C. Blanco, Evaluation of LiFePO4 Batteries for Electric Vehicle Applications, IEEE Trans. Ind. Appl. 51 (2015) 1855-1863. doi:10.1109/TIA.2014.2344446.

[61] I.V. Thorat, Understanding Performance--Limiting Mechanisms in Li-ION Batteries for High-Rate Applications, Provo, Utah, 2009.

[62] A. Lasia, Electrochemical Impedance Spectroscopy and its Applications, London, 2014.

[63] Boston University, AC Source and ..., (2016) 3-5. http://physics.bu.edu/ duffy/semester2/c20_AC.html.

[64] K.R. Cooper, M. Smith, Electrical test methods for on-line fuel cell ohmic resistance measurement, J. Power Sources. 160 (2006) 10881095. doi:10.1016/j.jpowsour.2006.02.086.

[65] S. Prabhakaran, C.R. Sullivan, Impedance-Analyzer Measurements of High-Frequency Power Passives :, (2002) 1360-1367.

[66] Y. Zhang, C.Y. Wang, X. Tang, Cycling degradation of an automotive LiFePO4 lithium-ion battery, J. Power Sources. 196 (2011) 1513-1520. doi:10.1016/j.jpowsour.2010.08.070.

[67] M. Safari, C. Delacourt, Aging of a Commercial Graphite/LiFePO4 Cell, J. Electrochem. Soc. 158 (2011) A1123. doi: 10.1149/1.3614529.

[68] M. Klett, R. Eriksson, J. Groot, P. Svens, K. Ciosek Högström, R.W. Lindström, H. Berg, T. Gustafson, G. Lindbergh, K. Edström, Non-uniform aging of cycled commercial LiFePO4//graphite cylindrical cells revealed by post-mortem analysis, J. Power Sources. 257 (2014) 126-137. doi:10.1016/j.jpowsour.2014.01.105.

[69] H.G. Schweiger, O. Obeidi, O. Komesker, A. Raschke, M. Schiemann, C. Zehner, M. Gehnen, M. Keller, P. Birke, Comparison of several methods for determining the internal resistance of lithium ion cells, Sensors. 10 (2010) 5604-5625. doi:10.3390/s100605604.

[70] J. Huang, Z. Li, B.Y. Liaw, J. Zhang, Graphical analysis of electrochemical impedance spectroscopy data in Bode and Nyquist representations, J. Power Sources. 309 (2016) 82-98. doi:10.1016/j.jpowsour.2016.01.073.

[71] T. Note, Understanding the Specifications of your Potentiostat, (2016) 1-6. http://www.gamry.com/applicationnotes/instrumentation/understanding-specs-of-potentiostat/.

[72] C. Edouard, M. Petit, C. Forgez, J. Bernard, R. Revel, Parameter sensitivity analysis of a simplified electrochemical and thermal model for Li-ion batteries aging, J. Power Sources. 325 (2016) 482 494. doi:10.1016/j.jpowsour.2016.06.030.

[73] V. García Fernández, C. Blanco Viejo, D. Anseán González, M. González Vega, Y. Fernández Pulido, J. Alvarez Antón, Thermal Analysis of a Fast Charging Technique for a High Power LithiumIon Cell, Batteries. 2 (2016) 32. doi:10.3390/batteries2040032. 